\title{
Beclin 1 expression is associated with the occurrence and development of esophageal squamous cell carcinoma
}

\author{
HAILEI DU ${ }^{1 *}$, JIAMIN $\mathrm{CHE}^{1 *}$, MINMIN SHI $^{2}$, LIANGGANG ZHU ${ }^{1}$, \\ JUN BIAO HANG ${ }^{1}$, ZHONGYUAN CHEN $^{1}$ and HECHENG LI ${ }^{1}$ \\ ${ }^{1}$ Department of Thoracic Surgery, Ruijin Hospital; ${ }^{2}$ Institute of Digestive Surgery, Shanghai \\ Jiao Tong University School of Medicine, Shanghai 200025, P.R. China
}

Received December 9, 2015; Accepted June 15, 2017

DOI: $10.3892 / \mathrm{ol} .2017 .7015$

\begin{abstract}
Beclin 1 has a central role in the regulation of autophagy, differentiation, apoptosis resistance, tumorigenesis and cancer progression. The role of Beclin 1 in the development of esophageal squamous cell carcinoma (ESCC) and its subsequent progression is not fully characterized. In the present study, the role of Beclin 1 and autophagy in ESCC was evaluated. The expression of Beclin $1 \mathrm{mRNA}$ and protein levels in human ESCC tumor and adjacent normal esophageal tissue was measured. Beclin $1 \mathrm{mRNA}$ and protein were significantly lower in tumor tissue than in normal esophageal tissue $(\mathrm{P}<0.05)$. Cells of the less differentiated esophageal tumors expressed lower Beclin $1 \mathrm{mRNA}$ and protein $(\mathrm{P}<0.05)$. Tumors from patients in early clinical stages (I/II) exhibited significantly higher Beclin 1 mRNA and protein expression levels than patients with tumors in mid-to-late stages (III/IV; $\mathrm{P}<0.05)$. Tumors from patients with lymph node metastasis exhibited significantly lower Beclin $1 \mathrm{mRNA}$ and protein expression levels compared with tumors from patients without lymph node involvement $(\mathrm{P}<0.05)$. Beclin 1 downregulation was demonstrated to significantly upregulate invasion by ESCC EC9706 cells $(\mathrm{P}<0.01)$, and downregulate the number of acidic vesicular organelles, a process associated with autophagy. These results suggest that the expression of Beclin 1 is associated with the occurrence and development of ESCC. Measuring the Beclin 1 expression of tumors from patient may improve the understanding of the prognosis of patients with ESCC.
\end{abstract}

Correspondence to: Professor Hecheng Li, Department of Thoracic Surgery, Ruijin Hospital, Shanghai Jiao Tong University School of Medicine, 197 Ruijin Er Road, Shanghai 200025, P.R. China

E-mail: drqwh2003@hotmail.com

*Contributed equally

Key words: Beclin 1, autophagy, esophageal squamous cell carcinoma

\section{Introduction}

Esophageal cancer is one of the most common types of cancer in a number of regions worldwide, particularly China, South America and Western Europe (1). Esophageal squamous cell carcinoma (ESCC) is the major histological subtype of esophageal cancer, which predominantly occurs in China (2). Multimodal treatment for patients with esophageal tumors has improved the survival rate and is regarded as the current standard of practice for patients following surgery (3-5). Neoadjuvant chemoradiotherapy improves resectability, reduces the extent of disease progression, and improves local control, disease-free survival and overall survival rates when compared with surgery alone (6-9). Despite improvements in surgical techniques, radiotherapy and chemotherapy, the prognosis for ESCC remains poor, with a 5-year survival rate of $<10 \%$ (10). This is frequently due to extra-esophageal invasion and/or local lymph node metastasis, which may present in the early stages of ESCC (11). The occurrence and development of esophageal tumors is caused by the cooperative action of a range of genes. Investigating the genes involved with the occurrence, development and metastasis of ESCC may improve the theoretical foundation of and identify potential targets for the treatment of this type of tumor.

Beclin 1 was the first mammalian autophagy protein to be described; it was identified as a homolog of an essential yeast autophagy gene (Atg6) (12). Beclin 1 was demonstrated to be a positive regulator of autophagy (13) and a haplo-insufficient tumor suppressor that commonly exhibits reduced expression or becomes monoallelically deleted in certain cancer types (14). However, the expression of Beclin 1 in ESCC tissues from patients, and its role in the occurrence and development of ESCC, have yet to be characterized. Furthermore, data regarding the effect of Beclin 1 expression on ESCC cell metastasis are not yet available.

In the present study, the expression of Beclin 1 mRNA and protein in ESCC tumor and adjacent normal esophageal tissue was investigated. It was identified that the expression of Beclin 1 protein is associated with ESCC progression. The downregulation of Beclin 1 was also demonstrated to be associated with the invasion and metastasis of ESCC cells. The results suggest that Beclin 1 may be a potential therapeutic target in ESCC. 


\section{Materials and methods}

Patients and tissues. A total of 126 specimens and adjacent normal tissues ( $>5 \mathrm{~cm}$ from the tumor tissue) obtained from the esophagectomy of primary ESCC tumors from January 2010 to September 2011 were collected from the Department of Thoracic Surgery, Ruijin Hospital, Shanghai Jiao Tong University School of Medicine (Shanghai, China). Fresh samples were stored immediately in liquid nitrogen. None of the patients had received preoperative chemotherapy, radiotherapy or other treatments. The histopathological characteristics of the 126 specimens were assessed.

Todetermine the disease stage according to the International Union Against Cancer Tumor, Node, Metastasis (TNM) classification system (15), pathology reports and clinical histories from the time of surgery were reviewed. The patient characteristics, including age, sex, tumor differentiation and TNM stage (including T, depth of tumor invasion; N, lymph node metastasis; and $\mathrm{M}$, distant metastasis) were evaluated. The patients included 92 males and 34 females and ranged in age from 45 to 80 years (median, 62 years). Approval for the study was granted by the Ruijin Hospital Ethics Committee. Informed written consent was obtained from all patients.

Reverse transcription-quantitative polymerase chain reaction (RT-qPCR). Changes in Beclin 1 mRNA expression were detected and quantified relative to GAPDH mRNA expression by qPCR. Total RNA from ESCC tumor and adjacent tissue was extracted using TRIzol reagent (Gibco; Thermo Fisher Scientific, Inc., Waltham, MA, USA) according to the manufacturer's protocol. qPCR testing was performed using a qPCR system (SYBR ${ }^{\circledR}$ Premix Ex TaqTM II; Takara Bio, Inc., Japan) according to the manufacturer's protocol. The primers for Beclin-1 and GAPDH were as follows: Beclin 1 forward, 5'-CTGAGGGATGGAAGGGTC-3' and reverse 5'-TGGGCT GTGGTA AGTAATG-3'; GAPDH forward, 5'-GAAGGT GAAGGTCGGAGTC-3' and reverse, 5'-GAAGATGGTGAT GGGATTTC-3'. Thermal cycling was performed with a $20-\mu 1$ reaction volume in the PRISM 7000 Sequence Detection system (Applied Biosystems; Thermo Fisher Scientific, Inc.). The PCR amplification conditions were as follows: $95^{\circ} \mathrm{C}$ for $10 \mathrm{~min}$, then 40 cycles of $95^{\circ} \mathrm{C}$ for $5 \mathrm{sec}$ and $60^{\circ} \mathrm{C}$ for $30 \mathrm{sec}$. The expression of Beclin $1 \mathrm{mRNA}$ was calculated and normalized against GAPDH mRNA expression (16); each data point was performed in triplicate. The mean value for Beclin 1 expression was used as the cut-off point to define high and low Beclin 1 expression.

Isolation of proteins and western blot analysis. A total of $50 \mu 1$ from each frozen tissue specimen was ground and homogenized in $1 \mathrm{ml}$ of radioimmunoprecipitation lysis buffer (RIPA; Santa Cruz Biotechnology, Inc., Dallas, TX, USA) with complete protease inhibitor cocktail tablets (Roche Diagnostics, Basel, Switzerland). The homogenate was put into $1.5 \mathrm{ml}$ centrifuge tubes and centrifuged at $16,000 \times \mathrm{g}$ for $30 \mathrm{~min}$ at $4^{\circ} \mathrm{C}$. The concentration of the supernatant was measured with the bicinchoninic acid protein assay (BCA) method. Total protein $(50 \mu \mathrm{g})$ was resolved by $10 \%$ SDS-PAGE separating gel and transferred onto $0.22 \mu \mathrm{m}$ polyvinylidene fluoride (PVDF) membranes. Subsequent to blocking in 5\% skim milk for $2 \mathrm{~h}$ at room temperature, the PVDF membranes were respectively probed with mouse monoclonal goat anti-human Beclin 1 (cat. no. sc-48341; 1:100; Santa Cruz Biotechnology, Inc.) and monoclonal mouse anti-GAPDH (cat. no. sc-47724; 1:5,000; Santa Cruz Biotechnology, Inc.) overnight at $4^{\circ} \mathrm{C}$.

Following washing in $1 \mathrm{X}$ TBST 3 times, the PVDF membranes were then incubated with HRP-labeled goat anti-mouse IgG secondary antibody (cat. no. sc-2039; 1:5,000; Santa Cruz Biotechnology) at room temperature for $1 \mathrm{~h}$ and then were washed with $0.5 \%$ I-Block blocking buffer (Thermo Fisher Scientific, Inc.). The blots were incubated with chemiluminescence substrate (EMD Millipore, Billerica, MA, USA) and detected by an enhanced chemiluminescence assay. Densitometry was performed using Photoshop software (CS6; Adobe Systems, Inc., San Jose, CA, USA), normalized to GAPDH from the same blot image. Blot images are representative of $\geq 3$ independent experiments.

Detection of acidic vesicular organelles (AVOs) with acridine orange staining. Acridine orange (Sigma-Alrich; Merck KGaA, Darmstadt, Germany) was added to the culture medium containing the human esophageal carcinoma EC0706 cell line (Shanghai Institutes for Biological Science of the Chinese Academy of Sciences, Shanghai, China) to a final concentration of $1 \mu \mathrm{g} / \mathrm{ml}$ and followed by incubation in the dark at $20^{\circ} \mathrm{C}$ for $15 \mathrm{~min}$. Samples were then examined under a fluorescence microscope. Acridine orange accumulation in acidic autophagic vacuoles caused the appearance of a granular distribution of bright red fluorescence in the cytoplasm, which was indicative of autophagosome formation. The extent of AVO fluorescence was measured with an excitation wavelength of $488 \mathrm{~nm}$ and an emission wavelength of $515 \mathrm{~nm}$. The relative amount of AVOs was quantitatively determined according to the red-to-green fluorescence ratio, which was obtained using Photoshop software.

Transfection of Beclin 1 siRNA into EC9706 cells and detection cell invasiveness and metastasis. A Beclin 1-targeting sense sequence and a universal negative control siRNA (cat. no. 12935-400) were purchased from Invitrogen (Thermo Fisher Scientic, Inc.). The targeting sequence for Beclin 1 (5'-GGGTCTAAGACGTCCAACA-3') and the negative control siRNA were cloned into the BamHI and EcoRI sites of the pGSU6-GFP vector (cat. no. GTP600300; Genlantis, Inc., San Diego, CA, USA). Control and siRNA plasmids, and a recombinant pcDNA3.1-Beclin 1 plasmid (provided by Professor Qin Ye from Shanghai Institute of Digestive Surgery, Shanghai Jiao Tong University School of Medicine) were transfected into the human esophageal carcinoma EC9706 cells in Dulbecco's modified Eagle's medium (DMEM; Gibco; Thermo Fisher Scientific, Inc.) with $10 \%$ fetal bovine serum (FBS; Gibco; Thermo Fisher Scientific, Inc.) without antibiotics at $5 \% \mathrm{CO}_{2}$ and $37^{\circ} \mathrm{C}$ once cells had reached $50 \%$ confluence into 6 -well plates using Lipofectamine $2000^{\circledR}$ (cat. no. 11668019; Invitrogen; Thermo Fisher Scientific, Inc.) according to the manufacturer's protocol. At $48 \mathrm{~h}$ following transfection, cells were washed with PBS three times. Whole cell lysate was extracted with RIPA lysis buffer, and then a western blot, as aforementioned, was performed to detect relative Beclin 1 
Table I. Beclin 1 mRNA expression in esophageal squamous cell carcinoma tissue and its association with clinicopathological factors.

\begin{tabular}{|c|c|c|c|c|}
\hline \multirow[b]{2}{*}{ Pathologic parameter } & \multirow[b]{2}{*}{ Cases, $\mathrm{n}$} & \multicolumn{2}{|c|}{$\begin{array}{c}\text { Beclin } 1 \text { mRNA } \\
\text { expression, } \mathrm{n}\end{array}$} & \multirow[b]{2}{*}{$\chi^{2}$} \\
\hline & & High & Low & \\
\hline Normal tissue & 126 & 117 & 9 & $31.48^{\mathrm{a}}$ \\
\hline Carcinoma tissue & 126 & 80 & 46 & \\
\hline \multicolumn{5}{|l|}{ Sex } \\
\hline Male & 92 & 45 & 47 & 0.03 \\
\hline Female & 34 & 16 & 18 & \\
\hline \multicolumn{5}{|l|}{ Size of tumor, $\mathrm{cm}$} \\
\hline$<3$ & 72 & 37 & 42 & 0.07 \\
\hline$\geq 3$ & 54 & 24 & 30 & \\
\hline \multicolumn{5}{|l|}{ Age, years } \\
\hline$<65$ & 40 & 18 & 22 & 0.79 \\
\hline$>65$ & 86 & 46 & 40 & \\
\hline Degree of differentiation & & & & $13.49^{\mathrm{a}}$ \\
\hline Well/moderately & 70 & 43 & 27 & \\
\hline Poorly & 56 & 16 & 40 & \\
\hline Pathologic stage & & & & $14.12^{\mathrm{a}}$ \\
\hline $\mathrm{I} / \mathrm{II}$ & 78 & 48 & 30 & \\
\hline III/IV & 48 & 13 & 35 & \\
\hline Lymph node & & & & $32.84^{\mathrm{a}}$ \\
\hline Negative & 52 & 41 & 11 & \\
\hline Positive & 74 & 20 & 54 & \\
\hline
\end{tabular}

${ }^{\mathrm{a}} \mathrm{P}<0.01$.

expression in each group, and to confirm the effectiveness of Beclin1 RNA interference or upregulation.

Invasion assay. For the invasion assay, the inserted Transwell chambers $(8.0 \mu \mathrm{m}$ pore size; Corning Incorporated, Corning, NY, USA) were pretreated with Matrigel ${ }^{\circledR}$ (diluted 1:6 in DMEM; BD Biosciences, Franklin Lakes, NJ, USA) for $2 \mathrm{~h}$ at $37^{\circ} \mathrm{C}$. Then, $6 \times 10^{4}$ cells in $200 \mu \mathrm{l}$ DMEM without serum were added in the upper chamber, while $600 \mu 1$ DMEM medium with $10 \%$ FBS was placed in the bottom of wells. Cells were incubated at $37^{\circ} \mathrm{C}$ with $5 \% \mathrm{CO}_{2}$ for $24 \mathrm{~h}$. Cells that did not move to the lower chamber were removed from the topside. The cells were then stained in $2 \%$ crystal violet solution for $15 \mathrm{~min}$ and immersed in PBS for $10 \mathrm{~min}$. Finally, the number of invading cells were counted under x200 fields using an inverted microscope (Leica Microsystems, Wetzlar, Germany). At least five random fields were selected, and the average number was taken. The data are presented as the mean \pm standard deviation.

Statistical analysis. Statistical analysis was performed using SPSS software (v.13.0; SPSS, Inc., Chicago, IL, USA). Data are expressed as the means \pm standard deviation of 3 individual experiments. Comparisons of quantitative data were
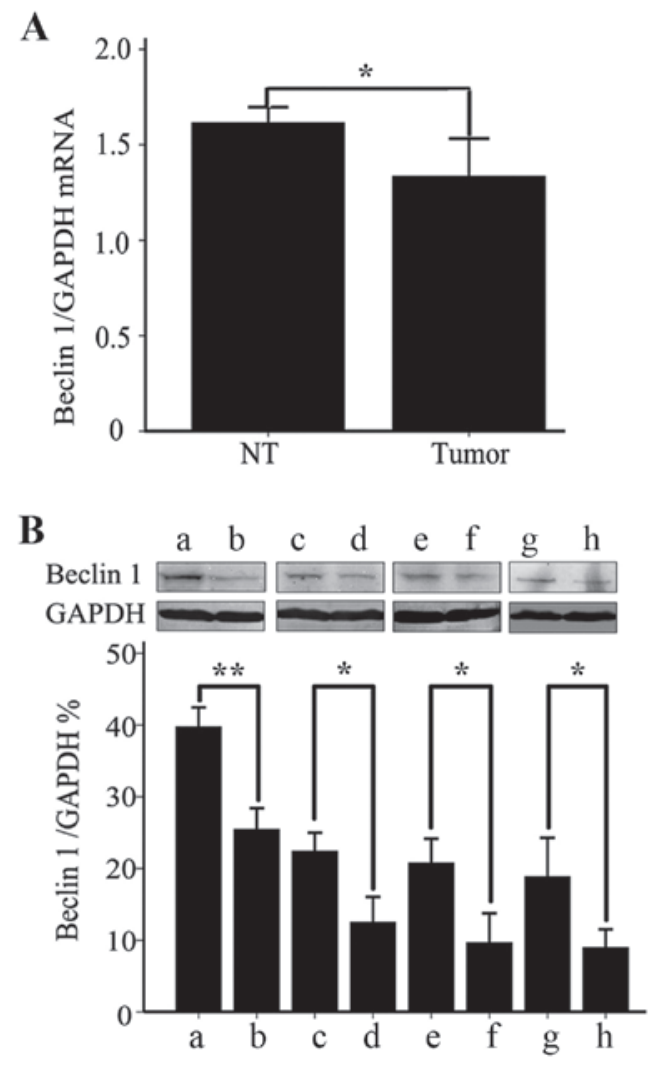

Figure 1. Expression of Beclin $1 \mathrm{mRNA}$ and protein in ESCC tumor and adjacent normal esophageal tissues, and its association with clinicopathological factors. (A) Beclin $1 \mathrm{mRNA}$ expression in ESCC tumor and adjacent normal esophageal tissues. (B) The association of Beclin 1 mRNA expression level with clinicopathological factors, including (a) adjacent normal esophageal tissue; (b) ESCC tissue; (c) highly and moderately differentiated tissue; (d) poorly differentiated tissue; (e) early stage (I/II) tumors; (f) mid-to-late stage (III/IV) tumors; (g) without lymph node metastasis; and (h) lymph node metastasis, as determined by western blot analysis. The data represent the mean \pm standard deviation of 3 independent experiments. ${ }^{*} \mathrm{P}<0.05,{ }^{* *} \mathrm{P}<0.01$. ESCC, esophageal squamous cell carcinoma.

analyzed using the $\chi^{2}$ and Student's t-tests between two groups or by one-way analysis of variance for multiple groups with Fisher's least significant difference post hoc test. A log-rank test was performed to compared two survival curves between two groups. $\mathrm{P}<0.05$ was considered to represent a statistically significant difference.

\section{Results}

Association between Beclin-1 mRNA expression and clinicopathological features. As summarized in Table I and Fig. 1A, the expression of Beclin 1 mRNA in ESCC tissue was significantly lower than in the adjacent normal esophageal tissue $(\mathrm{P}<0.05)$. Tumors that were less differentiated exhibited lower expression levels of Beclin 1 mRNA $(\mathrm{P}<0.05)$. Tumors from early stage (I/II) cancer presented with a significantly elevated expression of Beclin $1 \mathrm{mRNA}$ compared with tumors from later stage $(\mathrm{III} / \mathrm{IV})$ cancer $(\mathrm{P}<0.05)$. The expression level of Beclin $1 \mathrm{mRNA}$ was significantly lower in tumors from patients with lymph node metastasis than those without lymph node involvement $(\mathrm{P}<0.05)$. The expression level of Beclin 1 mRNA was not associated with a patient's age or sex, or the tumor size. 
Table II. Beclin 1 protein expressiom in esophageal squamous cell carcinoma tissue.

Beclin 1

Pathologic parameter Cases, $\mathrm{n}$ expression ${ }^{\mathrm{a}}, \%$ P-value

\begin{tabular}{lrrr}
\hline Type of tissue & & & $<0.01$ \\
$\quad$ Normal & 126 & $40.60 \pm 3.80$ & \\
$\quad$ Tumor & 126 & $25.32 \pm 2.65$ & \\
Degree of differentiation & & & $<0.05$ \\
$\quad$ Well/moderately & 70 & $22.27 \pm 2.34$ & \\
$\quad$ Poorly & 56 & $12.35 \pm 3.17$ & \\
Clinical stage & & & $<0.05$ \\
I/II & 78 & $20.63 \pm 3.05$ & \\
III/IV & 48 & $9.52 \pm 3.66$ & \\
Lymph node & & & $<0.05$ \\
$\quad$ Negative & 52 & $18.72 \pm 4.81$ & \\
Positive & 74 & $8.84 \pm 2.31$ & \\
\hline
\end{tabular}

${ }^{\mathrm{a}}$ Mean \pm standard deviation, relative to GAPDH. ${ }^{\mathrm{b}} \mathrm{Calculated}$ with Student's t-test.

Association between Beclin 1 protein expression and clinicopathological features. As summarized in Table II and Fig. 1B, the expression of Beclin 1 protein in ESCC tissue was significantly lower than in the adjacent normal esophageal tissue $(\mathrm{P}<0.05)$. Tumors that were less differentiated exhibited lower expression levels of Beclin 1 protein $(\mathrm{P}<0.05)$. The expression of Beclin 1 protein in the early stages (I/II) of the cancer was significantly higher than those in mid-to-late stages (III/IV; $\mathrm{P}<0.05)$. The expression of Beclin 1 protein in tumors from patients with lymph node metastasis was significantly lower than those without lymph node involvement $(\mathrm{P}<0.05)$. The expression level of Beclin 1 protein was not associated with a patient's age or sex, or the tumor size.

Confirmation of Beclin 1 overexpression or knockdown. The recombinant pcDNA3.1-Beclin 1 plasmid was transfected into EC9706 cells to induce overexpression of the Beclin 1 protein. In another group of EC9706 cells, the level of Beclin 1 protein was decreased by RNA interference. Beclin 1 overexpression or knockdown were confirmed using western blotting and the detection of AVOs with acridine orange. As demonstrated in in Fig. 2, the expression levels of Beclin 1 protein were significantly reduced in EC9706 cells transfected with Beclin 1 siRNA $(\mathrm{P}<0.05)$, whereas the level was significantly increased in EC9706 cells transfected with the pcDNA3.1-Beclin 1 plasmid $(\mathrm{P}<0.01)$.

Role of Beclin 1 expression level on the invasiveness of the EC9706 ESCC cell line. As included in Table III, the EC9706 cells transfected with pcDNA3.1-Beclin 1 exhibited a significant decrease in the number of invasive cells crossing the polycarbonate membrane of the Transwell invasion chamber $(\mathrm{P}<0.01)$, whereas the EC9706 cells transfected with Beclin 1 siRNA cells exhibited a significant increase in the number of invasive cells $(\mathrm{P}<0.01)$, compared with the untransfected control group.
$\mathbf{A}$

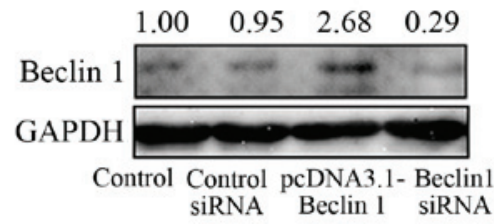

B
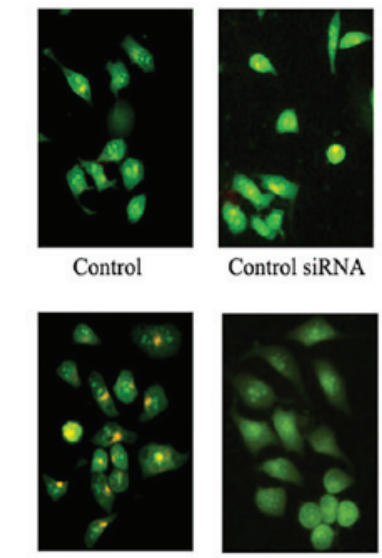

Control siRNA

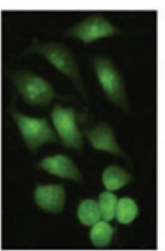

pcDNA3.1-Beclin 1 Beclin1 siRNA

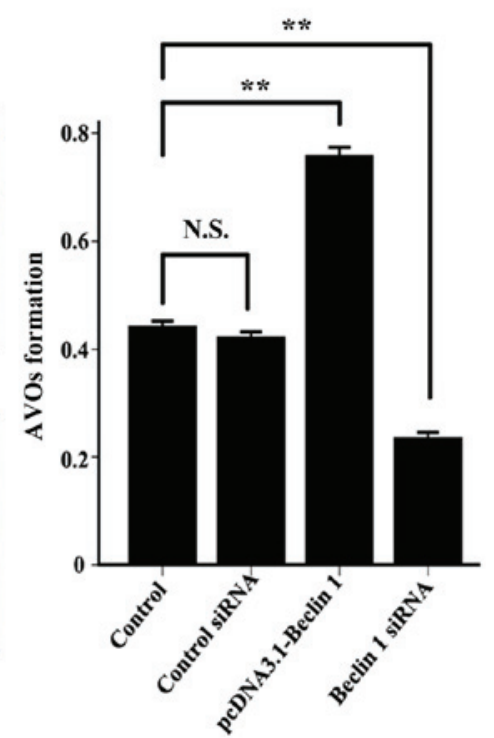

Figure 2. Confirmation of Beclin 1 overexpression or knockdown (A) Western blot analysis of Beclin 1 expression in EC9706 cells transfected with a Beclin 1 siRNA, control siRNA or a pcDNA3.1-Beclin 1 plasmid. (B) Detection of AVOs with acridine orange staining to determine the relative amount of Beclin 1 activity. The formation of AVOs was quantified with the detection of red and green fluorescence after acridine orange staining. The data are presented as the means \pm standard deviation from three independent experiments. ${ }^{* *} \mathrm{P}<0.01$. siRNA, small interfering RNA; AVO, acidic vesicular organelles; N.S., no significance.

The expression of Beclin 1 protein and cell invasiveness did not differ significantly between the untransfected and negative control siRNA control groups. These data indicated that an elevated expression level of Beclin 1 protein may decrease the invasiveness of the EC9706 cells, while a lowered expression level of Beclin 1 protein may promote the invasion of EC9706 cells.

Kaplan-Meier cumulative survival curve. The median follow-up period was 33.59 months, with a range of 8-69 months. The 1-, 2- and 3-year survival rates for the entire patient group were $93.65,58.73$ and $34.92 \%$, respectively. The survival rate of the Beclin 1-high group was significantly improved compared with the Beclin 1-low group $(\mathrm{P}<0.01$; Fig. 3).

\section{Discussion}

The reported pattern of Beclin 1 expression in gastrointestinal cancer is not consistent. Previous studies have reported that Beclin 1 and autophagy were suppressed in hepatocellular carcinoma and pancreatic cancer (17), but that they were elevated in colon and gastric cancer (18), compared with adjacent normal tissue. Ding et al (19) confirmed that the expression of Beclin 1 in liver cancer tissue was 
Table III. The association between the invasiveness of EC9706 esophageal squamous cell carcinoma cells with the relative expression of Beclin 1.

\begin{tabular}{lcc}
\hline Groups & Beclin 1 expression ${ }^{\mathrm{a}}, \%$ & Number of invasive cells \\
\hline Untransfected control group & $20.35 \pm 3.02$ & $243.32 \pm 38.23$ \\
Control siRNA-transfected group & $21.30 \pm 2.18$ & $225.36 \pm 28.16$ \\
pcDNA3.1-Beclin 1-transfected group & $38.34 \pm 5.25$ & $40.65 \pm 15.24^{\mathrm{b}}$ \\
Beclin 1 siRNA-transfected group & $5.65 \pm 1.27$ & $382.36 \pm 45.73^{\mathrm{b}}$ \\
\hline
\end{tabular}

${ }^{\mathrm{a}}$ Mean \pm standard deviation, relative to GAPDH. ${ }^{\mathrm{b}} \mathrm{P}<0.01$ vs. untransfected control group, calculated with one-way analysis of variance.

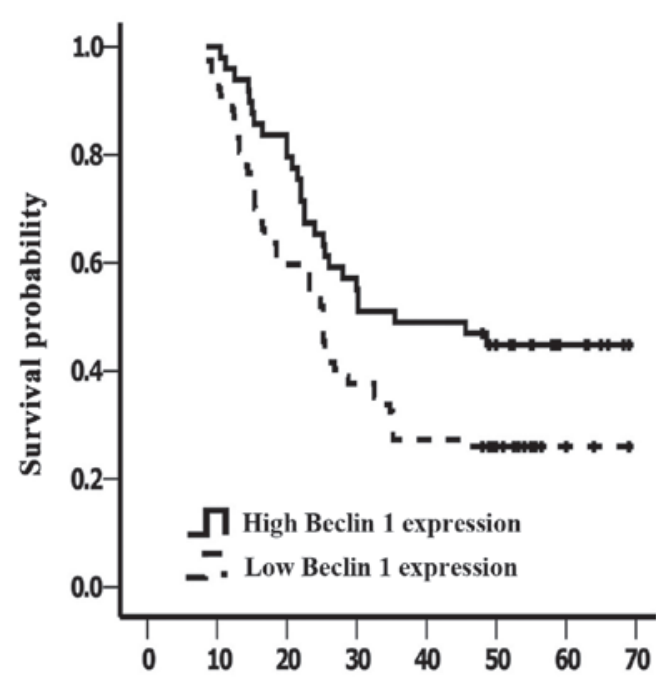

Figure 3. Cumulative Kaplan-Meier survival curves. Survival curves for patients with Beclin-1-high and Beclin-1-low expressing tumors, using the cut-off of the mean mRNA expression level. Check marks represent censored data.

significantly decreased compared with adjacent tissue, and that Beclin 1 expression was associated with the occurrence and development of liver cancer. In the present study, it was determined that the level of mRNA Beclin 1 expression relative to GAPDH in ESCC tissue and adjacent normal tissues in patients was 63.49 and $92.85 \%$, respectively. The expression of Beclin $1 \mathrm{mRNA}$ and protein in ESCC were significantly downregulated compared with adjacent normal esophageal tissue $(\mathrm{P}<0.05)$. The more highly undifferentiated esophageal cells demonstrated lower expression levels of Beclin 1 mRNA and protein $(\mathrm{P}<0.05)$. The expression levels of Beclin $1 \mathrm{mRNA}$ and protein were significantly higher in patients with early stage tumors (I/II; $\mathrm{P}<0.05)$. The expression levels of Beclin $1 \mathrm{mRNA}$ and protein in tumors from patients with lymph node metastasis were significantly decreased vs. tumors from patients without lymph node metastasis $(\mathrm{P}<0.05)$.

Furthermore, the association between Beclin 1 expression and clinicopathological factors was assessed in 126 patients with ESCC. A high expression of Beclin 1, as determined by the mean expression level, was observed in $63.5 \%$ of ESCC tumors. Lymph node metastasis, the degree of tumor differentiation and the clinical stage were significantly associated with Beclin-1 expression; however, there was no significant difference in the expression of Beclin 1 associated with other features (age, sex, and size of primary carcinoma; Tables I and II). Previous study has revealed that autophagy serves an important role in many physiological functions; defects in this process have been linked to many types of cancer $(20,21)$. Beclin 1, an autophagy execution protein, is considered a tumor suppressor protein in tumor biology $(14,22,23)$. The reduction of Beclin 1 expression in tumor tissue observed in the present study may be associated with the function of basal autophagy in maintaining homeostasis in normal tissue $(20,21)$. Studies in transgenic mouse models have shown that the monoallelic deletion of Beclin 1 promotes tumor development (24). The growth of colorectal cancer cells that overexpress Beclin 1 was observed to be reduced compared with mock-transfected cells (25). Beclin 1 deficiency is also associated with increased angiogenesis $(26,27)$.

In the present study, EC9706 cells were transfected with the pcDNA3.1-Beclin 1 plasmid or a Beclin 1 siRNA. Changes in cell invasiveness in these cells were then observed; EC9706 cells transfected with the pcDNA3.1-Beclin 1 plasmid were confirmed to overexpress Beclin 1 protein $(\mathrm{P}<0.01)$ and a significantly reduced number of cells crossed the Transwell chamber compared with the empty vector-transfected and untransfected control groups $(\mathrm{P}<0.01)$. EC9706 cells transfected with Beclin 1 siRNA exhibited significantly reduced Beclin 1 protein expression $(\mathrm{P}<0.01)$ and a significantly increased number of cells crossing the Transwell chamber compared with the control siRNA-transfected and the untransfected control groups $(\mathrm{P}<0.01)$. These results indicated that downregulating Beclin 1 may promote cell invasion, while upregulating Beclin 1 may reduce the invasiveness. We hypothesize that Beclin 1 is a microtubule-associated protein, and that it may regulate cell motility through modulating the stability of microtubules.

Surgical resection followed by multimodal therapy is considered as the standard treatment for patients with localized ESCC (3-5). However, the problem of how to identify the patients likely to benefit from surgery is unresolved. In the present study, the elevated expression of Beclin 1 was identified as a favorable prognostic factor for ESCC patients.

In conclusion, it was identified that the expression of Beclin 1 is associated with the progression of ESCC, and that Beclin 1 upregulation is associated with a reduction in the invasive capabilities of ESCC cells. Examining the expression of Beclin 1 may contribute to improving the understanding of the prognosis of ESCC, and Beclin 1 may be a potential therapeutic target for treating ESCC. 


\section{Acknowledgements}

The present study was supported by the Shanghai Ruijin North Hospital Fund (2014ZY05) and Shanghai Charity Foundation for Cancer Research. The authors would like to thank Dr Zhiyong Du, Dr Songling Yu, Dr Guiyang Zhang and Dr Guangtao Sun from the Department of Thoracic Surgery, Ruijin Hospital, Shanghai Jiao Tong University School of Medicine (Shanghai, China) for the collection of ESCC specimens and discussion during research.

\section{References}

1. Pickens A and Orringer MB: Geographical distribution and racial disparity in esophageal cancer. Ann Thorac Surg 76: S1367-S1369, 2003

2. Zhang J, Jiang Y, Wu C, Cai S, Wang R, Zhen Y, Chen S, Zhao K, Huang Y, Luketich J and Chen H: Comparison of clinicopathologic features and survival between eastern and western population with esophageal squamous cell carcinoma. J Thorac Dis 7: 1780-1786, 2015

3. Cui Z, Tian Y, He B, Li H, Li D, Liu J, Cai H, Lou J, Jiang H, Shen $\mathrm{X}$ and Peng K: Associated factors of radiation pneumonitis induced by precise radiotherapy in 186 elderly patients with esophageal cancer. Int J Clin Exp Med 8: 16646-16651, 2015.

4. Nasr JY and Schoen RE: Prevalence of adenocarcinoma at esophagectomy for Barrett's esophagus with high grade dysplasia. J Gastrointest Oncol 2: 34-38, 2011.

5. Wagner TD, Khushalani N and Yang GY: Clinical T2NOMO carcinoma of thoracic esophagus. J Thorac Dis 2: 36-42, 2010.

6. Jabbour SK and Thomas CR Jr: Radiation therapy in the postoperative management of esophageal cancer. J Gastrointest Oncol 1: 102-111, 2010

7. Das P: Esophageal cancer: Is preoperative chemoradiation the new standard? J Gastrointest Oncol 1: 68-69, 2010.

8. Kleinberg L: Does postoperative radiation therapy benefit patients with esophageal cancer? J Gastrointest Oncol 1: 70-71, 2010.

9. Prasanna PG, Stone HB, Wong RS, Capala J, Bernhard EJ, Vikram B and Coleman CN: Normal tissue protection for improving radiotherapy: Where are the gaps? Transl Cancer Res 1: $35-48,2012$.

10. Sun GP, Wan X, Xu SP, Wang H, Liu SH and Wang ZG: Antiproliferation and apoptosis induction of paeonol in human esophageal cancer cell lines. Dis Esophagus 21: 723-729, 2008.

11. Yu C, Fan S, Sun Y and Pickwell-Macpherson E: The potential of terahertz imaging for cancer diagnosis: A review of investigations to date. Quant Imaging Med Surg 2: 33-45, 2012.

12. Yue Z, Jin S, Yang C, Levine AJ and Heintz N: Beclin 1, an autophagy gene essential for early embryonic development, is a haploinsufficient tumor suppressor. Proc Natl Acad Sci USA 100 15077-15082, 2003.
13. Huang W, Choi W, Hu W, Mi N, Guo Q, Ma M, Liu M, Tian Y, Lu P, Wang FL, et al: Crystal structure and biochemical analyses reveal Beclin 1 as a novel membrane binding protein. Cell Res 22: 473-489, 2012.

14. Yang MC, Wang HC, Hou YC, Tung HL, Chiu TJ and Shan YS Blockade of autophagy reduces pancreatic cancer stem cell activity and potentiates the tumoricidal effect of gemcitabine. Mol Cancer 14: 179, 2015.

15. Talsma K, van Hagen P, Grotenhuis BA, Steyerberg EW, Tilanus HW, van Lanschot JJ and Wijnhoven BP: Comparison of the 6th and 7th editions of the UICC-AJCC TNM classification for esophageal cancer. Ann Surg Oncol 19: 2142-2148, 2012.

16. Du H, Yang W, Chen L, Shen B, Peng C, Li H, Ann DK, Yen Y and Qiu W: Emerging role of autophagy during ischemia-hypoxia and reperfusion in hepatocellular carcinoma. Int J Oncol 40: 2049-2057, 2012

17. Fiorini C, Cordani M, Gotte G, Picone D and Donadelli M: Onconase induces autophagy sensitizing pancreatic cancer cells to gemcitabine and activates Akt/mTOR pathway in a ROS-dependent manner. Biochim Biophys Acta 1853: 549-560, 2015.

18. Li BX, Li CY, Peng RQ, Wu XJ, Wang HY, Wan DS, Zhu XF and Zhang XS: The expression of beclin 1 is associated with favorable prognosis in stage IIIB colon cancers. Autophagy 5: 303-306, 2009.

19. Ding ZB, Shi YH, Zhou J, Qiu SJ, Xu Y, Dai Z, Shi GM, Wang XY, Ke AW, Wu B and Fan J: Association of autophagy defect with a malignant phenotype and poor prognosis of hepatocellular carcinoma. Cancer Res 68: 9167-9175, 2008.

20. Levine B and Kroemer G: Autophagy in the pathogenesis of disease. Cell 132: 27-42, 2008.

21. Mathew R, Karantza-Wadsworth V and White E: Role of autophagy in cancer. Nat Rev Cancer 7: 961-967, 2007.

22. Koneri K, Goi T, Hirono Y, Katayama K and Yamaguchi A: Beclin 1 gene inhibits tumor growth in colon cancer cell lines. Anticancer Res 27: 1453-1457, 2007.

23. Toton E, Lisiak N, Sawicka P and Rybczynska M: Beclin-1 and its role as a target for anticancer therapy. J Physiol Pharmacol 65: 459-467, 2014.

24. Qu X, Yu J, Bhagat G, Furuya N, Hibshoosh H, Troxel A, Rosen J, Eskelinen EL, Mizushima N, Ohsumi Y, et al: Promotion of tumorigenesis by heterozygous disruption of the beclin 1 autophagy gene. J Clin Invest 112: 1809-1820, 2003.

25. Burada F, Nicoli ER, Ciurea ME, Uscatu DC, Ioana M and Gheonea DI: Autophagy in colorectal cancer: An important switch from physiology to pathology. World J Gastrointest Oncol 7: 271-284, 2015.

26. Teng RJ, Du J, Welak S, Guan T, Eis A, Shi Y and Konduri GG: Cross talk between NADPH oxidase and autophagy in pulmonary artery endothelial cells with intrauterine persistent pulmonary hypertension. Am J Physiol Lung Cell Mol Physiol 302: L651-L663, 2012.

27. Lee SJ, Kim HP, Jin Y, Choi AM and Ryter SW: Beclin 1 deficiency is associated with increased hypoxia-induced angiogenesis. Autophagy 7: 829-839, 2011. 